\title{
Effect of ulcerative colitis and smoking on rectal blood flow
}

\author{
E D Srivastava, M A H Russell, C Feyerabend, J Rhodes
}

\begin{abstract}
Rectal blood flow was measured by laser doppler flowmetry over 60 minutes in eight patients with colitis in remission and eight healthy male non-smokers. Ten smokers were also examined on two occasions, one of which included smoking a cigarette. Plasma nicotine concentrations were measured in smokers. All subjects showed a pronounced fall in rectal blood flow in the first $\mathbf{3 0}$ minutes and patients with colitis had significantly higher values compared with smokers $(p<0.002 ; p<0.04)$ and non-smokers $(p<0.007 ; p<0.002)$ during the first and second 30 minutes respectively. Values in smokers and non-smokers were similar, but smoking a cigarette was associated with a significant fall in blood flow $(p<0.04)$ and this change was inversely related to the rise in plasma nicotine concentration $(r=-0.63 ; p<0.05)$. The findings may be relevant to the association between colitis and the smoking history.
\end{abstract}

The aetiology of ulcerative colitis remains unknown, although it is now recognised as a disease predominantly involving non-smokers ${ }^{1}$ and ex-smokers. ${ }^{2}$ If the smoking status determines whether ulcerative colitis develops, it is pertinent to examine mechanisms which may be involved. With this in mind we have examined the effect of smoking on rectal blood flow including appropriate controls and patients with colitis.

\section{Methods}

\section{SUBJECTS}

Eight patients with ulcerative colitis (seven men and one woman, mean age 39 years, range 26-51 years), all non-smokers with distal colitis in remission, were examined; they were receiving sulphasalazine or mesalazine only; eight healthy male non-smokers (mean age 34, range 21-48 years) and 10 healthy men smokers (mean age 45 , range 21-66 years), who smoked at least 10 cigarettes daily, were also examined. The control subjects, smokers, and non-smokers were receiving no medication. Preliminary studies showed that in patients with active ulcerative colitis blood and mucus affected the recording by obliterating the signal, thus only patients with colitis in remission were studied, giving a continuous uninterrupted reading.

Addiction Research nstitute of Psychiatry, London

M A H Russel

C Feyerabend

Correspondence to:

Professor John Rhodes.

Accepted for publication 15 November 1989
Rectal blood flow was measured in volts by lase doppler flowmetry with an angled probe (Peri- flux PF2, PF 110, angle probe, Perimed, Stockholm, Sweden), mounted in portex tubing with an external diameter of $6.6 \mathrm{~mm}$ (Fig 1). A side arm was attached at right angles to the probe and was taped in the natal cleft to maintain the probe position while records were made.

The probe was inserted $5 \mathrm{~cm}$ from the anal margin using a modified proctoscope which had an $8 \mathrm{~mm}$ strip cut from the shaft of the scope. This made it possible to insert the proctoscope, visualise clean mucosa on the anterior rectal wall, position the probe, and then withdraw the scope.

Rectal blood flow was measured for 60 minutes in each subject and smokers had two sets of measurements, one of which involved smoking a cigarette at 30 minutes. The order of these two sessions in smokers was randomised. All smokers had completed smoking their cigarette within five minutes and no cigarette had been smoked in the previous two hours. Subjects smoked their usual brand and were instructed to inhale as deeply as possible. Preliminary studies showed an early pronounced fall in rectal blood flow after the proctoscope was introduced, but this reached a plateau after 20 to 30 minutes. In view of this, smokers were asked to have their cigarette 30 minutes after the probe was inserted and venous blood was taken for measurement of plasma nicotine concentration ${ }^{3}$ at $30,35,40,45$, 50,55 , and 60 minutes; when they did not smoke, samples were taken at 30 and 60 minutes. Ten $\mathrm{ml}$ venous blood was taken on each occasion via a cannula.

STATISTICAL ANALYSIS

Standard methods of analysis were used includ-



Figure 1: The probe for measurement of blood flow was mounted in portex tubing with the head $5 \mathrm{~cm}$ from the anal margin. A side arm was taped in the natal cleft to maintain the position of the probe head in relation to mucosa. 
ing paired and unpaired $t$ tests and parametric (Pearson) correlation coefficients.

\section{Results}

Each group of subjects showed a steady fall in rectal blood flow which was usually limited to the first 20 minutes. Mean values for patients with ulcerative colitis were higher than for the other groups throughout the 60 minutes (Fig 2) and differences were significant during both the first $(\mathrm{p}<0.002)$ and the second $(\mathrm{p}<0.04) 30$ minute periods (Table I).

Blood flow measurements in control subjects, smokers, and non-smokers were similar and overall values in the first and second 30 minute periods did not differ significantly between the groups. Smoking, however, was associated with a significant fall in blood flow of 0.13 volts between 28 and 59 minutes $(p<0.04)$. During experiments where smokers did not smoke there was a significant rise after 16 minutes, wheras the blood flow in non-smokers continued to fall (Fig 2).

After smoking there was a pronounced rise in plasma nicotine concentration with peak values between 30 and 35 minutes followed by a steady fall over the remaining 25 minutes (Fig 3 ). When subjects were not smoking there was no significant change in the plasma nicotine concentration between 30 and 60 minutes. The maximum fall in mucosal blood flow was related to the maximum rise in plasma nicotine concentration $(r=-$ $0.63 ; p<0.05$; Figure 4) but was not related to the peak or mean concentrations of nicotine between 30 to 60 minutes.

\section{Discussion}

The consistent fall in rectal blood flow which occurred in the first 20 to 30 minutes probably reflects a return to normal of changes which

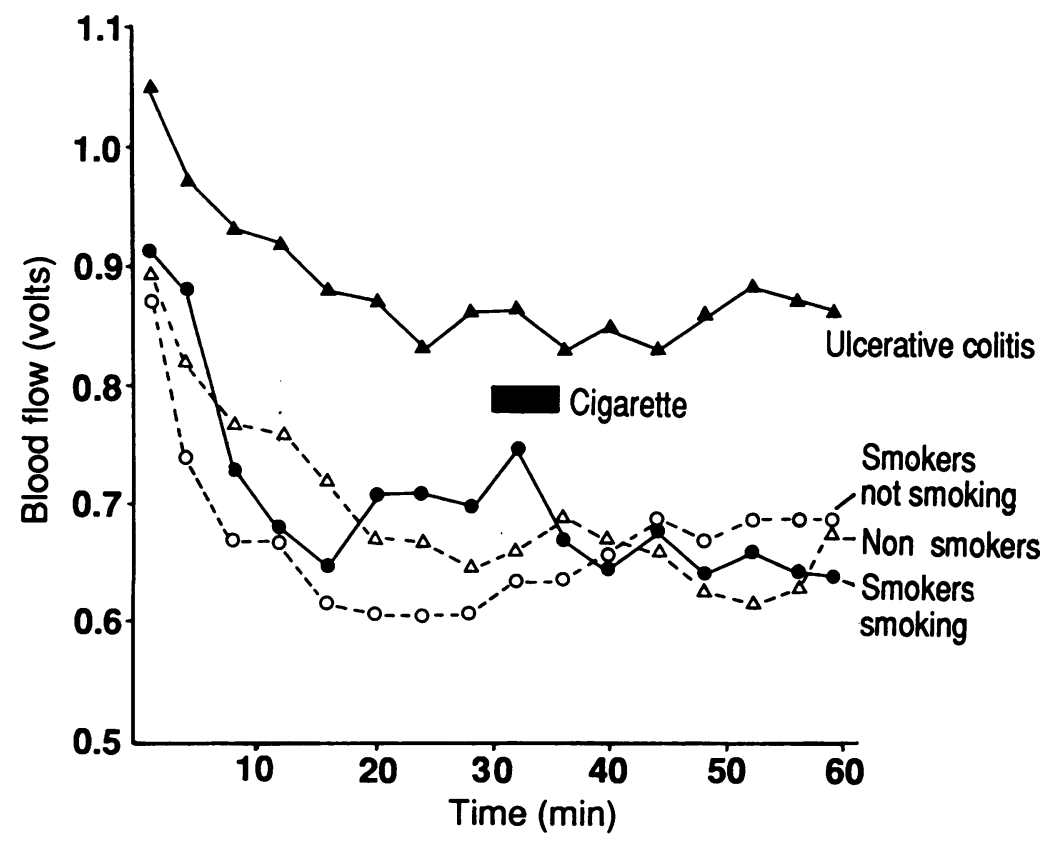

Figure 2: Mean rectal blood flow measured with a laser doppler probe and recorded in volts continuously over 60 minutes in eight patients with ulcerative colitis, eight healthy male non-smokers, and 10 healthy male smokers. Recordings were made twice in smokers, on one occasion smoking a cigarette at 30 minutes. followed the proctoscopic examination. Blood flow in the ulcerative colitis group was consistently higher than in the control groups which were similar. Smoking was accompanied by a fall in the rectal blood flow, which in turn was related to the rise which occurred in the plasma nicotine concentration in individual patients.

The laser doppler technology for measuring mucosal blood flow has proved sensitive and reproducible in carefully controlled experimental studies in the human colon during surgery. ${ }^{4}$ The method has been criticised, however, because the laser beam penetrates mucosa 6 $\mathrm{mm},{ }^{6}$ and recorded changes in blood flow may be due to changes at different levels which cannot be quantified. Records are also subject to wide variations from artefacts which accompany movement or adjustment of the probe. Measurements over a long period, however, with patients in the left lateral position gave steady records and superimposed changes probably reflect rectal blood flow rather than artefact, which is easily recognised because of its abrupt nature. The probe was placed over clean mucosa and its position within the portex tube ensured that while in contact with the mucosa there was a gap of $2 \mathrm{~mm}$ between the probe surface and the mucosa.

The equipment had a signal level indicator and a lamp which changed colour when the probe position was more than $6 \mathrm{~mm}$ from the mucosal surface, but this rarely occurred. Records over a long period made it possible to achieve a stable measurement of mucosal blood flow. All colitis patients were in remission and after preliminary work our records were made in a standardised manner to limit variations which might invalidate the findings. After smoking the rectal blood flow did not fall in all subjects, but falls that occurred were related to rises in plasma nicotine concentration; in six subjects the fall was between -0.02 volts and -0.28 volts and associated with a rise in the plasma nicotine concentration of over $22 \mathrm{ng} / \mathrm{ml}$. Among four subjects whose rectal blood flow did not fall, the nicotine concentrations rose in two but showed only minor change in the other two. The mean peak plasma concentrations of nicotine were higher than previously reported ${ }^{5}$ (Table II), which may be due to the subjects smoking the cigarette quickly (within five minutes) with blood levels recorded while smoking; initial measurements are usually delayed until two minutes after completion of smoking.

Rectal blood flow in smokers was higher in the first 30 minutes before a cigarette was smoked than in experiments where subjects did not smoke; we can only suggest that the increase which was observed in four of the subjects before smoking may be some form of anticipatory phenomenon comparable with salivation before eating food. This suggestion is made because there was no significant difference in plasma nicotine concentration at $\mathbf{3 0}$ minutes in the two series of experiments with smokers. The fall in blood flow which followed smoking appeared to be independent of any rise in blood flow before smoking.

When subjects began to smoke there was an initial rise in blood flow which may have been 
TABLE I Rectal blood flow (mean (SD)) measured in volts in eight patients with ulcerative colitis and eight non-smokers and 10 smokers. p values are given to identify values which differed significantly

\begin{tabular}{|c|c|c|c|}
\hline Group & $\begin{array}{l}\text { Mean first } \\
30 \text { mins }\end{array}$ & $\begin{array}{l}\text { Mean second } \\
30 \text { mins }\end{array}$ & $\begin{array}{l}\text { Difference between } \\
28 \text { and } 60 \text { mins }\end{array}$ \\
\hline $\begin{array}{l}\text { Ulcerative colitis } \\
\qquad \\
\text { non-smokers }\end{array}$ & $\begin{array}{c}0.92(0.07) \\
v \\
0.75(0.13) \\
(p<0.007)\end{array}$ & $\begin{array}{c}0.86(0.11) \\
v \\
0.64(0.10) \\
(\mathrm{p}<0.002)\end{array}$ & $\begin{array}{c}-0.01(0.05) \\
v \\
-0.08(0.13) \\
(\mathrm{NS})\end{array}$ \\
\hline $\begin{array}{c}\text { Ulcerative colitis } \\
v \\
\text { smokers smoking }\end{array}$ & $\begin{array}{c}0.92(0.07) \\
v \\
0.75(0.12) \\
(\mathrm{p}<0.002)\end{array}$ & $\begin{array}{l}0.86(0.11) \\
v \\
0.66(0.23) \\
(\mathrm{p}<0.04)\end{array}$ & $\begin{array}{c}-0.01(0.05) \\
v \\
-0.06(0.15) \\
(\mathrm{NS})\end{array}$ \\
\hline $\begin{array}{l}\text { Ulcerative colitis } \\
v \\
\text { smokers not smoking }\end{array}$ & $\begin{array}{c}0.92(0.07) \\
v \\
0.68(0 \cdot 18) \\
(p<0.002)\end{array}$ & $\begin{array}{l}0.86(0.11) \\
v \\
0.67(0.22) \\
(\mathrm{p}<0.04)\end{array}$ & $\begin{array}{c}-0.01(0.05) \\
v \\
0.07(0.15) \\
(\mathrm{NS})\end{array}$ \\
\hline $\begin{array}{l}\text { Non-smokers } \\
v \\
\text { smokers smoking }\end{array}$ & $\begin{array}{l}0.75(0 \cdot 13) \\
v \\
0 \cdot 75(0 \cdot 12) \\
(N S)\end{array}$ & $\begin{array}{l}0.64(0.10) \\
v \\
0.66(0.23) \\
(N S)\end{array}$ & $\begin{array}{c}-0.08(0 \cdot 13) \\
v \\
-0.06(0.15) \\
(\mathrm{NS})\end{array}$ \\
\hline $\begin{array}{l}\text { Non-smokers } \\
v \\
\text { Smokers not smoking }\end{array}$ & $\begin{array}{l}0.75(0 \cdot 13) \\
v \\
0.68(0 \cdot 18) \\
(N S)\end{array}$ & $\begin{array}{l}0.64(0 \cdot 10) \\
v \\
0.67(0.22) \\
(N S)\end{array}$ & $\begin{array}{c}-0.08(0.13) \\
v \\
0.07(0.15) \\
(p<0.04)\end{array}$ \\
\hline $\begin{array}{l}\text { Smokers smoking } \\
v \\
\text { smokers not smoking }\end{array}$ & $\begin{array}{l}0.75(0 \cdot 12) \\
v \\
0.68(0 \cdot 18) \\
(N S)\end{array}$ & $\begin{array}{l}0.66(0.23) \\
v \\
0.67(0.22) \\
(\mathrm{NS})\end{array}$ & $\begin{array}{c}-0.06(0.15) \\
v \\
0.07(0.15) \\
(\mathrm{p}<0.04)\end{array}$ \\
\hline
\end{tabular}

NS= not significant

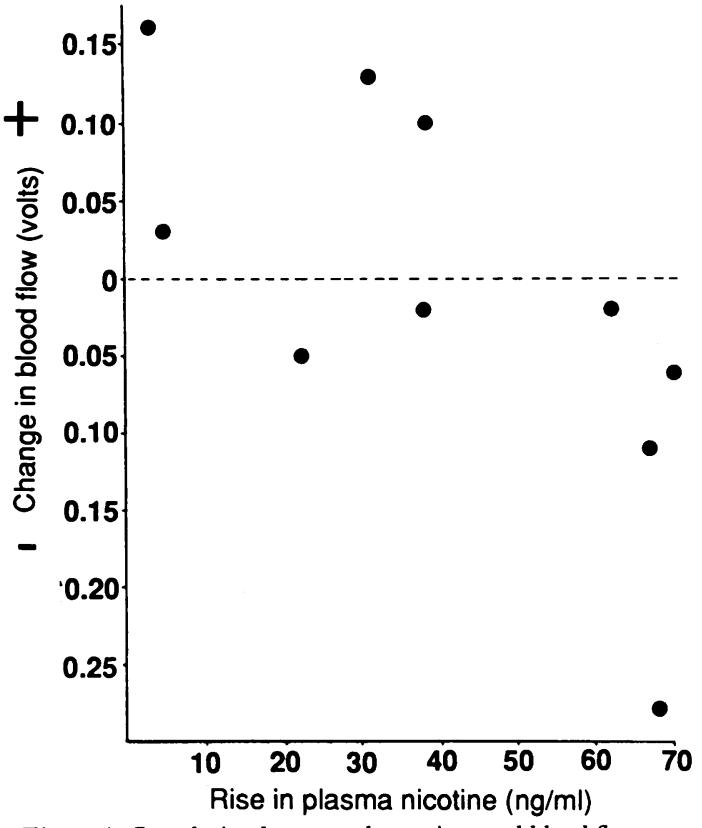

Figure 4: Correlation between change in rectal blood flow measured with a laser doppler probe in 10 healthy male smokers at 6 minutes after smoking a cigarette with the maximum rise in plasma nicotine after smoking $(r=-0.63$; $p<0 \cdot 05)$

TABLE II Plasma nicotine concentrations $(\mathrm{ng} / \mathrm{ml})$ in 10 healthy male smokers during measurement of rectal blood flow. Values were obtained at 30 and 60 minutes while not smoking and at more frequent intervals after smoking a cigarette at 30 minutes

\begin{tabular}{llr}
\hline Time (mins) & $\begin{array}{l}\text { Mean }(S D) \\
(\mathrm{ng} / \mathrm{ml})\end{array}$ & $\begin{array}{l}\text { Range } \\
(\mathrm{ng} / \mathrm{ml})\end{array}$ \\
\hline After smoking: & & \\
30 & $14 \cdot 2(5 \cdot 4)$ & $2 \cdot 4-22 \cdot 3$ \\
35 & $53 \cdot 0(29 \cdot 1)$ & $6 \cdot 8-84 \cdot 8$ \\
40 & $47 \cdot 3(18 \cdot 6)$ & $35 \cdot 0-64 \cdot 2$ \\
45 & $36 \cdot 7(15 \cdot 4)$ & $7 \cdot 7-58 \cdot 6$ \\
50 & $31 \cdot 5(11 \cdot 9)$ & $7 \cdot 3-43 \cdot 0$ \\
55 & $29 \cdot 3(11 \cdot 9)$ & $6 \cdot 5-47 \cdot 5$ \\
60 & $26 \cdot 3(10 \cdot 0)$ & $6 \cdot 0-37 \cdot 7$ \\
Mean 30 to 60 & $33 \cdot 7(13 \cdot 8)$ & $6 \cdot 3-50 \cdot 5$ \\
Peak values & $54 \cdot 9(28 \cdot 4)$ & $7 \cdot 7-93 \cdot 0$ \\
Maximum rise & $40 \cdot 8(25 \cdot 9)$ & $3 \cdot 1-70 \cdot 7$ \\
Not smoking: & & \\
30 & $18 \cdot 8(9 \cdot 2)$ & $2 \cdot 9-33 \cdot 7$ \\
60 & $14 \cdot 2(6 \cdot 7)$ & $3 \cdot 3-26 \cdot 5$ \\
\hline
\end{tabular}

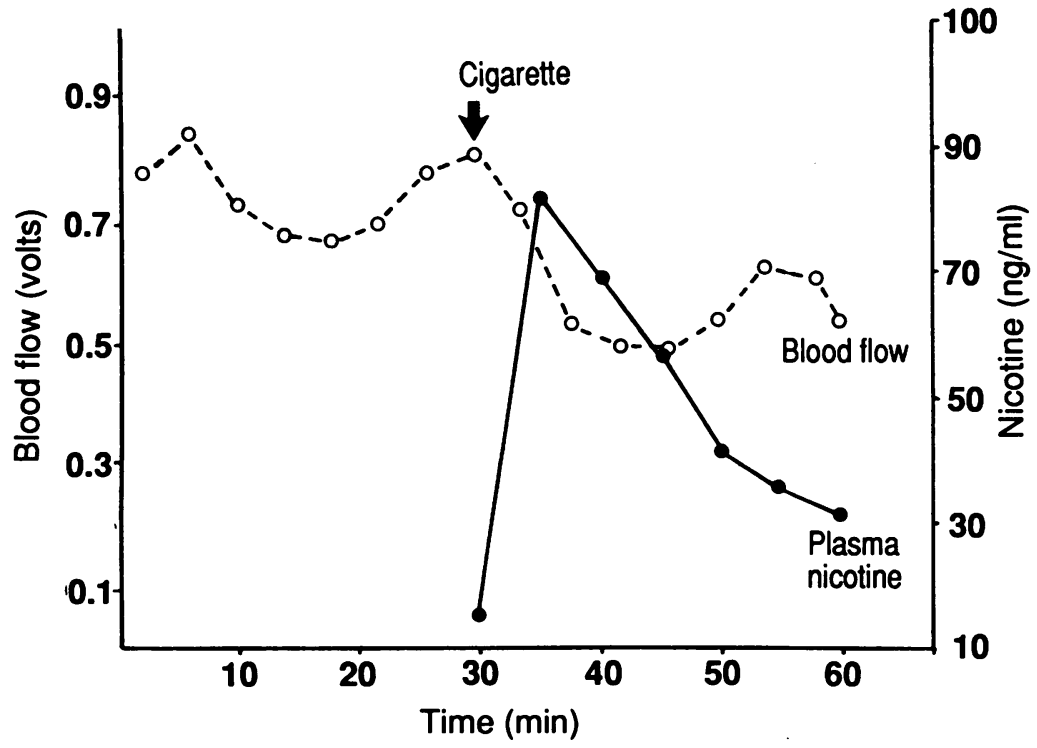

Figure 3: Rectal blood flow measured with a laser doppler probe in a healthy man who smoked a cigarette at 30 minutes. Plasma nicotine concentrations are recorded before and for 30 minutes after smoking. due to a minor change in the probe position, because early deep inhalation was associated with visible tightening of the anus around the probe; this was only evident for the first few minutes. Previous work has shown a rise in blood flow after mechanical stimulation of the colonic also observed a significant increase with measurements from the serosal surface of bowel after instrumentation of the lumen, including colonoscopy.

Our mean (SD) values for blood flow are lower than those recorded in the stomach, ${ }^{8} 7.9(2.5)$ volts, jejunum $7 \cdot 6(2 \cdot 9)$ volts, ileum $6 \cdot 1(2 \cdot 6)$ volts, and colon ${ }^{+} 5 \cdot 4(2 \cdot 3)$ volts, but confirm previous reports of higher values in proctitis and ulcerative colitis. ${ }^{10}$ "I

Although the sample size was small, the data show that smoking reduces rectal blood flow; this is probably due to nicotine induced vasoconstriction associated with a transient rise in blood pressure. ${ }^{12}$ Comparable work on the effect of smoking and nicotine on blood flow to other organs has shown constriction in cutaneous blood vessels with decreased blood flow to the hands and feet ${ }^{1+15}$; skin temperature is a good indicator of cutaneous blood flow and both finger tip and toe temperatures fall consistently after exposure to nicotine. Skin temperatures during and after a nicotine infusion are closely related to absolute values of plasma nicotine with no evidence of tolerance. ${ }^{16}$ In smokers with coronary heart disease the normal pattern of nicotine induced increase in coronary blood flow is converted to a decrease in flow which involves the area at risk of underperfusion due to coronary artery stenosis. ${ }^{17}$ Although not yet proved directly by angiography, all available data are consistent with the concept that underperfusion which follows smoking is due to increased vascular tone at the site of the critical stenosis. mucosa in both animals and humans. ${ }^{7}$ Ahn et al 
A reduction in rectal blood flow induced by smoking may be one of the mechanisms whereby smoking influences the clinical course of ulcerative colitis. Precisely how this affects pathogenesis is open to speculation, but changes in blood flow may reduce amounts of inflammatory mediators reaching the mucosal surface.

Patients with ulcerative colitis who do not smoke have reduced mucus production compared with non-smoking controls, but colitis patients who smoke have similar rates of production to controls. ${ }^{19}$ Smoking could conceivably increase mucus production and improve the mucus barrier in addition to reducing rectal blood flow.

We thank Professor R Marks, Department of Dermatology, for use of the laser doppler flowmeter.

I Harries AD, Baird A, Rhodes J. Non-smoking: a feature of ulcerative colitis. Br Med f 1982; 284: 706.

2 Motley RJ, Rhodes J, Jay S, Morris TJ. Late presentation of ulcerative colitis in ex-smokers. Int $\mathcal{f}$ Color Dis 1988; 3 : 171-5.

3 Feyerabend C, Russell MAH. Assay of nicotine in biological materials: sources of contamination and their elimination. 7 Pharm Pharmacol 1980; 32: 178-81.

4 Ahn H, Lindhagen J, Lundgren $\mathrm{O}$. Measurement of colonic blood flow with laser doppler flowmetry. Scand $\mathcal{F}$ Gastro enterol 1986; 7: 871-80.

5 Feyerabend C, Ings RM, Russell MAH. Nicotine pharmacokinetics and its application to intake from smoking. $\mathrm{Br} \mathcal{F ~ C l i n}$ Pharmacol 1985; 19: 239-47.

6 Johansson K, Ahn H, Lindhagen J, Lundgren O. Tissue penetration and measuring depth of laser doppler flowmetry 22: $1081-8$.
7 Fasth S, Hulten L, Lundgren O, Nordgren S. Vascular responses to mechanical stimulation of the mucosa of the cat colon. Acta Physiol Scand 1977; 101: 98-104.

8 Ahn $\mathrm{H}$, Ivarsson LE, Johannson $\mathrm{K}$, Lindhagen J, Lundgren $O$. Assessment of gastric blood flow with laser dopple flowmetry. Scand $\mathcal{F}$ Gastroenterol 1988; 23: 1203-10.

9 Ahn H, Lindhaghen J, Nilsson GE, Oberg PA, Lundgren $O$ Assessment of blood flow in the small intestine with lase doppler flowmetry. Scand F Gastroenterol 1986; 21: 863-70.

10 Lamont GL, Harrison JD, Morris DL. Rectal mucosal blood flow is increased in proctitis. [Abstract]. Gut 1988; 29 A1466.

11 Loft DE, Shorrock CJ, Riley SA, Rees WDW. Endoscopic evaluation of human colonic blood flow in health and inflammatory bowel disease. [Abstract]. Gut 1988; 29. A1491.

12 Sonnenfield $T$, Wennmalm $A$. Inhibition by nicotine of the formation of prostacyclin-like activity in rabbit and human formation of prostacyclin-like activity in rabbit and
vascular tissue. Brf Pharmacol 1980; 71: 609-13.

13 Benowitz NL, Kuyt F, Jacob P. Influence of nicotine on cardiovascular and hormonal effects of smoking. Clin cardiovascular and hormonal

14 Roth GM, McDonald JB, Sheard C. The effect of smoking cigarettes and intravenous administration of nicotine on the electrocardiogram, basal metabolic rate, cutaneous temperature, blood pressure and pulse rate of normal persons ЭAMA 1944; 125: 761-7.

15 Eckstein JW, Wood JE, Wilkins RW. Comparative vasoconstrictive effects of inhaling tobacco smoke in warm and cool environments and before and after abstinence from tobacco. Am Heart 7 1957; 53: 455-62.

16 Benowitz NL, Jacob P III, Jones RT, Rosenberg J. Interindividual variability in the metabolism and cardiovascular effects of nicotine in man. $\mathcal{F}$ Pharmacol Exp Ther 1982; 221: effects of

17 Maouad J, Fernandez F, Barrillon A, Gerbaux A, Gay J Diffuse or segmental narrowing (spasm) of the coronary arteries during smoking demonstrated on angiography. $A m$ $\mathcal{f}$ Cardiol 1984; 53: 354-5.

18 Nicod P, Rehr R, Winniford MD, Campbell WB, Firth BG Hillis LD. Acute systemic and coronary haemodynamic and serologic responses to cigarette smoking in long-term smokers with atherosclerotic coronary artery disease. 7 Am Coll Cardiol 1984; 4: 964-71.

19 Cope GF, Heatley RV, Kelleher J. Smoking and colonic mucus in ulcerative colitis. BrMed $\mathcal{F}$ 1986; 293: 481 . 